\title{
PROGRESS IN THE DEVELOPMENT AND PRODUCTION OF NANOSCALE IRON-COATING CATALYSTS
}

\author{
D. W. Matson \\ J. C. Linehan \\ J. G. Darab . \\ H. C. Catrob \\ E. Lui \\ M. R. Phelps \\ M. O. Hogan
}

April 1995

Presented at the

Ultrafine Particle Catalysts Conference

April 2-7, 1995

Anaheim, California

Prepared for

the U.S. Department of Energy

under Contract DE-AC06-76RLO 1830

Pacific Northwest Laboratory
Richland, Washington 99352

\section{DISCLAIMER}

This report was prepared as an account of work sponsored by an agency of the United States Government. Neither the United States Government nor any agency thereof, nor any of their employees, makes any warranty, express or implied, or assumes any legal liability or responsibility for the accuracy, completeness, or usefulness of any information, apparatus, product, or process disclosed, or represents that its use would not infringe privately owned rights. Reference herein to any specific commercial product, process, or service by trade name, trademark, manufacturer, or otherwise does not necessarily constitute or imply its endorsement, recommendation, or favoring by the United States Government or any agency thereof. The views and opinions of authors expressed herein do not necessarily state or reflect those of the United States Government or any agency thereof. 


\section{DISCLAMIER}

Portions of this document may be illegible in electronic image products. Images are produced from the best available original document. 


\title{
PROGRESS IN THE DEVELOPMENT AND PRODUCTION OF NANOSCALE IRON-CONTAINING CATALYSTS
}

\author{
Dean W. Matson, John C. Linehan, John G. Darab, Heather M. Watrob, \\ Eddie G. Lui, Max R. Phelps, and Michael O. Hogan \\ Pacific Northwest Laboratory 1 \\ PO Box 999 \\ Richland, WA 99352
}

Keywords: iron-based catalysts, nanocrystalline catalysts, hydrothermal synthesis, model compounds

\section{INTRODUCTION}

The development of effective iron-based powders for use as dispersed catalysts or as precursors to the active catalyst phase in direct coal liquefaction processes is an ongoing area of research. $2-4$ Although they are generally catalytically inferior to the more expensive catalyst materials based on molybdenum, cobalt, or nickel, iron-based powders offer the distinct advantages of relative low cost and toxicity. These factors make the prospects for using iron-based powders as one-time "throw away" catalysts attractive for large scale liquefaction operations since the costs associated with catalyst recovery could be avoided. Recent efforts have been aimed at increasing the efficiency of iron-based materials for coal liquefaction applications. Research has been focused on the development of ultrafine powders having very high specific surface areas and high dispersion in liquefaction media, ${ }^{4}$ and on the effect of iron oxyhydroxide phase toward conversion of precursors to the active catalyst phase under liquefaction conditions. 5

At the Pacific Northwest Laboratory (PNL) we have undertaken a program to investigate nanocrystalline iron-based powders as catalytic precursors in a variety of hydrocracking reactions, including coal liquefaction. One ultrafine powder synthesis method developed at PNL, the Rapid Thermal Decomposition of precursors in Solution (RTDS) process, appears to be particularly promising for use in the large scale production of nanocrystalline powders. 6,7 Using model compounds we have demonstrated that iron-based RTDS powders can be used to produce highly active carbon-carbon bond scission catalysts under reaction conditions relevant to coal liquefaction processes. 7,8 In this paper we present recent results of attempts at modifying the activity of RTDS-generated iron-based catalyst powders by doping with other metals and the results of scaleup efforts to produce kilogram quantities of active catalyst precursor by this process.

\section{CATALYST PRECURSOR POWDER SYNTHESIS}

When operated with an aqueous solvent, the RTDS powder synthesis method can be described as a continuous flow-through hydrothermal process. It involves the formation of ultrafine solid particles when homogeneous pressurized solutions are rapidly forced through a heated small diameter linear reactor (1-30 sec residence time). Under these conditions, well-known hydrothermal reactions, leading to nucleation of solid oxides or hydroxides, occur between dissolved metal species and the solvent ${ }^{9}$ Particle growth is quenched at the end of the reactor by passing the RTDS solution through an orifice, abruptly removing it from the hydrothermal environment. RTDS products are collected as aqueous suspensions in a cooled vessel, and typically contain submicrometer-sized aggregates of nanometer-sized crystallites. The solid powders can be separated from the suspension by centrifugation, spray drying, or freeze drying. Details of the RTDS process have been presented elsewhere. ${ }^{6-8}$ 
rivL currenuy nas two operauonal KIUS units. Une or these is reterred to as a bench-scale unit and is used primarily for quick response feasibility studies and small batch (1-10 liters of precursor solution) sample processing. The reactor tube in this unit consists of a 1 to 2 meter length of $1 / 8$ inch O.D. stainless steel high pressure tubing. Typical feedstock consumption rates and reaction residence times are 50-75 cc/min and 1-5 sec, respectively. The second RTDS system is referred to as an engineering-scale unit and has a larger reactor volume (with residence times of 5-30 sec) and greater throughput capacity $(150-250 \mathrm{cc} / \mathrm{min})$. In this system the reactor tube is a 2.25 meter length of 9/16 inch O.D. high pressure stainless steel tubing. The engineering-scale unit is used exclusively for runs involving greater than 10 liters of precursor solution.

While a range of iron-based oxide and oxyhydroxide phases can be produced using the RTDS method, we have targeted one phase, 6 -line ferrihydrite, 10 as a candidate for large scale production as a coal liquefaction catalyst precursor. Preliminary tests have shown that this phase is consistently active as a liquefaction catalyst precursor, 5,8 and that it is particularly amenable to preparation using the RTDS method. Although 6 -line jerrihydrite can also be produced using standard laboratory synthesis methods, 11 these are batch processes that are not necessarily scalable to larger batch sizes. Furthermore, benchtop 6-line ferrihydrite synthesis requires a time consuming dialysis step that can be eliminated by using the continuous RTDS method. We have investigated enhancing the rate of 6-line ferrihydrite production on the engineering-scale RTDS unit by increasing the iron salt content in the feed solution from $0.1 \mathrm{M}$ to as high as $0.5 \mathrm{M}$.

In addition to single phase metal oxides and oxyhydroxides, mixed or doped oxide/oxyhydroxide powders are easily produced by the appropriate choice and loadings of dissolved solute in the RTDS feed solution. We evaluated the RTDS method for making 6-line ferrihydrite doped with 10 
mole percent or less of an additional metal using the bench-scale RTDS apparatus. All doped 6line ferrihydrite samples were prepared using a $0.1 \mathrm{M}$ ferric nitrate solution as the iron source, and urea $(0.5 \mathrm{M})$ was added to the feed solution to raise the $\mathrm{pH}$ of the solution in the hydrothermal region. RTDS reaction temperatures used were $300 \pm 5^{\circ} \mathrm{C}$. The source of dopant metal ion and its nominal concentration in the feed solution are summarized in Table 1.

Unless otherwise noted, catalytic activities of all 6-line ferrihydrite powders reported in this work were evaluated using samples that had been separated from suspension by centrifugation, dried under flowing nitrogen, and ground and sieved to -325 mesh. Selected samples were calcined in air at $300^{\circ} \mathrm{C}$ for one hour. Catalytic evaluation of sample powders was undertaken by monitoring consumption of the model compound naphthylbibenzylmethane (NBBM) under a standard set of conditions. These tests were performed in sealed tubes containing $25 \mathrm{mg}$ of NBBM, $100 \mathrm{mg}$ of 9,10-dihydrophenanthrene, $3 \mathrm{mg}$ catalyst precursor and $3 \mathrm{mg}$ of sulfur. The tubes were suspended for $1 \mathrm{hr}$ in a sand bath at the desired reaction temperature. Phase analyses of RTDS products were performed using powder X-ray diffraction (XRD) and metal contents were analyzed by inductively coupled plasma/mass spectrometry (ICP/MS).

\section{RESULTS AND DISCUSSION}

The catalytic activity of RTDS-generated undoped 6-line ferrihydrite toward the consumption of NBBM is shown in Figure 1. The 6-line ferrihydrite catalyst precursor was ground and sieved, and the -325 mesh fraction was calcined at $300^{\circ} \mathrm{C}$ for $1 \mathrm{hr}$ prior to these tests. This figure clearly illustrates the high catalytic activity of this precursor phase at $400^{\circ} \mathrm{C}$, consuming essentially all of the model compound at that temperature. Furthermore, moderate activities were retained to reaction temperatures as low as $300^{\circ} \mathrm{C}$, where 30 percent of the model compound was consumed during a one hour reaction time.

ICP/MS analysis of powders produced by co-precipitation of iron and a second metal species in the presence of added urea using the bench-scale RTDS unit confirmed the usefulness of the RTDS technique for generating doped products of well-defined compositions (Table 1). XRD analysis of the doped powder products confirmed that 6 -line ferrihydrite was the primary crystalline phase present in the products. A minor hematite component was also detected in the tin-doped powder product.

In general, the greatest discrepancies between the nominal dopant contents in the RTDS feed solutions and the measured dopant contents of the dried powders were found in the samples having the smallest dopant contents ( 1 mole percent dopant metal). The primary source of these discrepancies most likely resulted from uncertainties in weighing the dopant salts when preparing the RTDS feed solutions. The analytical results on the doped ferrihydrite products indicate that essentially all of the iron and the dopant metal present in the feel solutions are precipitated in the RTDS unit and that doping levels closely follow the feed concentrations. This suggests that the RTDS process could be very valuable for the co-processing of semi-precious or precious metal catalysts on supports or, as in this case, the production of co-catalysts. The fine control over doping levels exhibited by the RTDS process has important prospective applications beyond coal liquefaction catalyst production. Many different catalysts are mixtures of two or more active species where the exact composition is important to promote both increased reactivity and lower costs. In RTDS experiments with zirconia as the major product constituent similar doping results have been obtained. 
Catalyst testing results measuring consumption of the NBBM model compound using the doped 6 -line ferrihydrite powders as catalyst precursors are presented in Figure 2 . The result of catalyst evaluation of an undoped RTDS 6-line ferrihydrite powder produced under comparable conditions is presented for comparison. When using the centrifuged, dried, and sieved powders as catalyst precursors without calcination (Fig. 2), NBBM consumptions approaching 90 percent and above were observed for chromium, zirconium, and molybdenum doped powders. Cobalt and nickel doped 6-line ferrihydrite products exhibited a range of intermediate to poor activities with the 10 percent nickel product consuming less than 20 percent of the model compound. The tin-doped product that was tested exhibited no apparent activity toward consumption of NBBM whatsoever. We speculate that this was due the presence of residual chlorine (a known catalyst poison) from the salt used as the source of tin ions in the RTDS solution.

$\mathrm{XRD}$ analysis of the samples calcined at $300^{\circ} \mathrm{C}$ for $1 \mathrm{hr}$ indicated that ferrihydrite remained the predominant phase after calcination. Those uncalcined samples exhibiting strong catalytic activity all lost less than 15 percent of their weight upon calcination while those with low activity lost up to 30 percent of their weight, most likely due to adsorbed water. The presence of excess adsorbed water may be detrimental to catalytically enhanced C-C bond scission reactions in the test system. An additional point can be made, however, that loadings of catalyst precursor samples containing excess adsorbed water would contain a correspondingly lower metals content, potentially reducing the measured catalytic activity per unit mass of catalyst precursor powder.

Calcination of the doped 6-line ferrihydrite samples produced a significant improvement in the measured catalytic activities of samples having mediocre activities in the uncalcined state (Fig. 2). Upon calcination, two of the cobalt doped powders consumed more than 90 percent of the model compound. The 10 percent nickel doped sample showed significant improvement as a result of calcination, increasing from less than 20 percent to nearly 70 percent consumption of the NBBM. Those powders previously exhibiting high activity retained that activity after calcination and no 
improvement was noted in the activity of the tin doped sample. The undoped ferrihydrite sample also showed an increase in activity with calcination even though the weight loss was only 6 percent. The activity toward NBBM consumption increased from 68 percent to over 90 percent.

Undoped 6-line ferrihydrite powders were produced using the engineering-scale RTDS reactor at increasing RTDS reaction temperatures to evaluate the effects of this variable using a constant 0.1 $\mathrm{M}$ ferric nitrate/0.5 M urea feed solution. Product suspensions produced at increasing temperatures starting at $255^{\circ} \mathrm{C}$ and increasing to $315^{\circ} \mathrm{C}$ were split into two fractions, one centrifuged and dried as summarized above, and the other spray dried in a bench-scale spray drying unit. Both splits were calcined at $300^{\circ} \mathrm{C}$ before catalyst testing. When evaluated for catalytic activity (Fig. 3 ) all of the centrifuged samples promoted NBBM consumptions in excess of 90 percent. Spray dried samples of the same products were generally somewhat inferior catalysts, likely resulting from incorporation of water soluble salts into the spray dried powders. This incorporation of salts in the powder could cover some percentage of the otherwise available catalytic sites and would also reduce the effective metal content per gram of catalyst powder. If spray dried RTDS products are to be used for coal liquefaction applications, catalyst loadings may be required to compensate for this effect.

Efforts at increasing the production rate of 6-line ferrihydrite powders with the engineering scale unit were focused on use of higher concentrations of ferric ion in the feed solution. Ferric nitrate concentrations ranging from $0.1 \mathrm{M}$ to $0.5 \mathrm{M}$ with a constant urea-to- $\mathrm{Fe}^{3+}$ ratio of $5: 1$ were used as feedstocks for these experiments. At the flow rates of the RTDS unit the $0.5 \mathrm{M}$ ferric ion concentration corresponded to a $1 \mathrm{lb}$ of dried powder-per-hour rate of production. The catalytic activities of these powders, as a function of the production rate, before and after calcination are shown in Figure 4. Notice that there is little difference in the activity of the calcined and uncalcined powders up to the highest production rate. Powders produced at $0.8 \mathrm{lb} / \mathrm{hr}$ showed some of the highest catalytic activities measured for iron oxide powders.

\section{SUMMARY}

The RTDS powder synthesis method has been shown suitable for producing nanocrystalline 6-line ferrihydrite powders that are highly active as precursors to catalysts promoting carbon-carbon bond scission reactions in coal model compounds. Activity of the ferrihydrite powder is maximized if it is sieved to fine aggregate size and pretreated at $300^{\circ} \mathrm{C}$ prior to use as a catalyst precursor. This material has been shown to exhibit catalytic activity at reaction temperatures as low as $300^{\circ} \mathrm{C}$. We have demonstrated the capability to generate the ferrihydrite powder product at rates of up to $1 \mathrm{lb} / \mathrm{hr}$ using an engineering-scale RTDS unit. The method has also been demonstrated to be capable of producing ferrihydrite powders accurately doped with a second metal component that may modify the catalyst characteristics.

\section{ACKNOWLEDGMENTS}

This work was supported by the U.S. Department of Energy, Office of Fossil Energy. Support for EGL and HMW was provided by the Associated Western Universities, Inc., Northwest Division under Grant DE-FG06-89ER-75522 with the U.S. Department of Energy. 


\section{REFERENCES}

(1) Pacific Northwest Laboratory is operated for the US Department of Energy by the Battelle Memorial Institute under contract DE-AC06-76RLO 1830.

(2) Rabo, J.A., in Advanced Heterogeneous Catalysts for Energy Applications Vol. II, U.S. DOE report DOE/ER-30201-H1, 1994, p. 1.1.

(3) Pradhan, V.R.; Tierney, J.W.; Wender, I.; and Huffman, G.P., Energy and Fuels, 1991, 5, 497.

(4) Derbyshire, F., Energy and Fuels, 1989, 3, 273.

(5) Linehan, J.C.; Matson, D.W.; and Darab, J.G., Energy and Fuels, 1994, 8, 56.

(6) Matson, D.W.; Linehan, J.C.; Bean, R.M.; Materials Letters 1992, 14, 222.

(7) Darab, J.G.; Buehler, M.F. ; Linehan, J.C.; and Matson, D.W., in Better Ceramics Through Chemistry VI, Materials Research Society symposium proceedings vol. 346, Cheetham, A.K., Brinker, C.J., Mecartney, M.L., and Sanchez, C., eds. Materials Research Society, pp. 499-510.

(8) Matson, D.W.; Linehan, J.C.; Darab, J.G.; and Buehler, M.F., Energy and Fuels, 1994, 8, 10.

(9) Rabenau, A., Angew. Chem., Int. Ed. Engl., 1985, 24, 1026.

(10) This weakly crystalline iron oxyhydroxide phase is named for the number of broad lines present in its powder XRD pattern.

(11) Schwertmann, U. and Cornell, R.M., Iron Oxides in the Laboratory, Weinheim; New York, 1991. 
Table I. Iron Oxides Doped with Transition Metals Produced by Co-Processing a.Second Metal Salt and 0.1 M Ferric Nitrate using RTDS

\begin{tabular}{|l|c|c|c|c|}
\multicolumn{1}{c}{$\begin{array}{c}\text { Nominal Mole } \\
\text { Percent Dopant } \\
\text { Metal in Feed }\end{array}$} & $\begin{array}{c}\text { Measured Mole } \\
\text { Percent Dopant } \\
\text { Metal in Isolated } \\
\text { Powder }\end{array}$ & $\begin{array}{c}\text { Percent } \\
\text { Difference } \\
\text { Between Feed } \\
\text { and Powder }\end{array}$ & $\begin{array}{c}\text { Phases Detected } \\
\text { by XRD }\end{array}$ \\
\hline Cobalt Acetate & 10 & 9.27 & 7 & 6-line Ferrihydrite \\
\hline Cobalt Acetate & 1 & 1.11 & 11 & 6-line Ferrihydrite \\
\hline $\mathrm{Ni}\left(\mathrm{NO}_{3}\right)_{2}$ & 10 & 9.82 & 2 & 6-line Ferrihydrite \\
\hline $\mathrm{Ni}\left(\mathrm{NO}_{3}\right)_{2}$ & 1 & 1.21 & 21 & 6-line Ferrihydrite \\
\hline $\mathrm{SnCl}_{2}$ & 1 & 1.10 & 10 & $\begin{array}{l}\text { 6-line Ferrihydrite/ } \\
\text { Hematite }\end{array}$ \\
\hline $\mathrm{Cr}\left(\mathrm{NO}_{3}\right)_{3}$ & 10 & 9.89 & 1 & 6-line Ferrihydrite \\
\hline $\mathrm{Cr}\left(\mathrm{NO}_{3}\right)_{3}$ & 1 & 1.23 & 23 & nd \\
\hline $\mathrm{ZrO}\left(\mathrm{NO}_{3}\right)_{2}$ & 10 & 9.36 & 6 & 6-line Ferrihydrite \\
\hline$\left(\mathrm{NH}_{4}\right)_{2} \mathrm{MOO}_{4}$ & 1 & -0.98 & 2 & 6-line Ferrihydrite \\
\hline
\end{tabular}

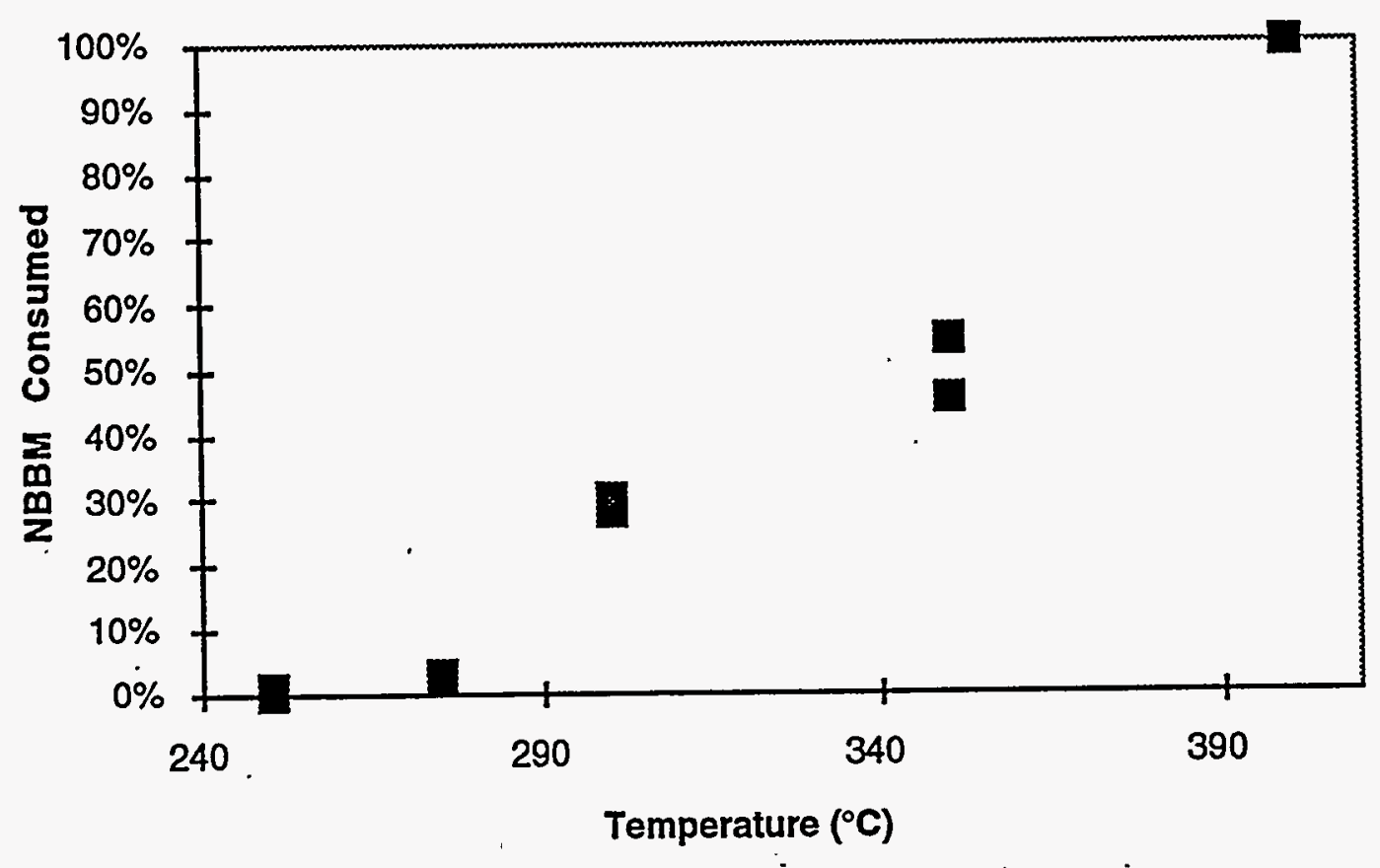


Figure 1. Effect of reaction temperature on catalytic activity of undoped RTDS-generated 6-line ferrihydrite toward consumption of NBBM model compound.

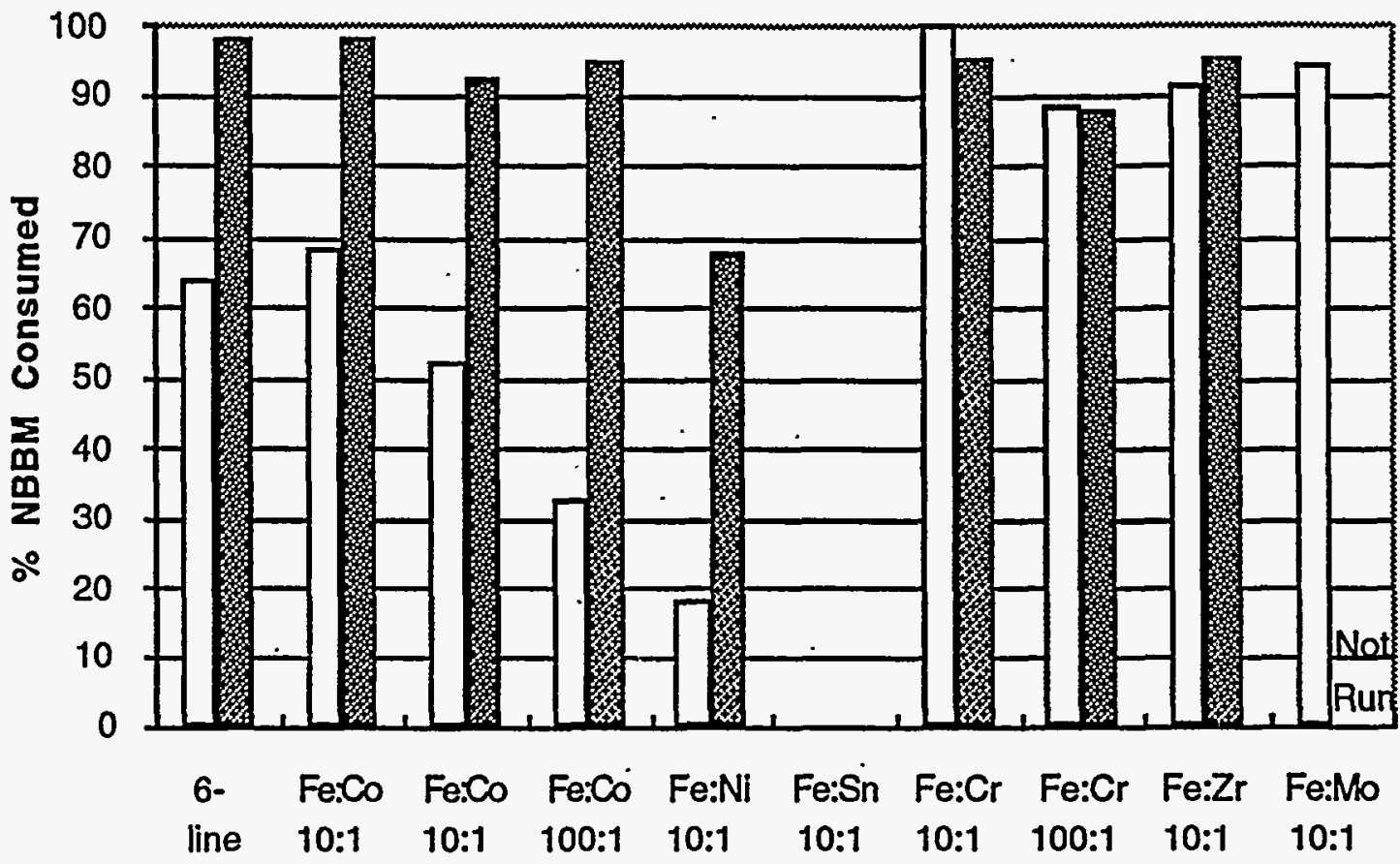

Figure 2. Effect of calcining at $300^{\circ} \mathrm{C}$ for one hour on activity of RTDS-generated 6-line ferrihydrite and doped 6-line ferrihydrite powders toward consumption of NBBM model compound at $400^{\circ} \mathrm{C}$. All samples were sieved to -325 mesh. Unshaded bars represent uncalcined powders, shaded bars represent calcined powders. 


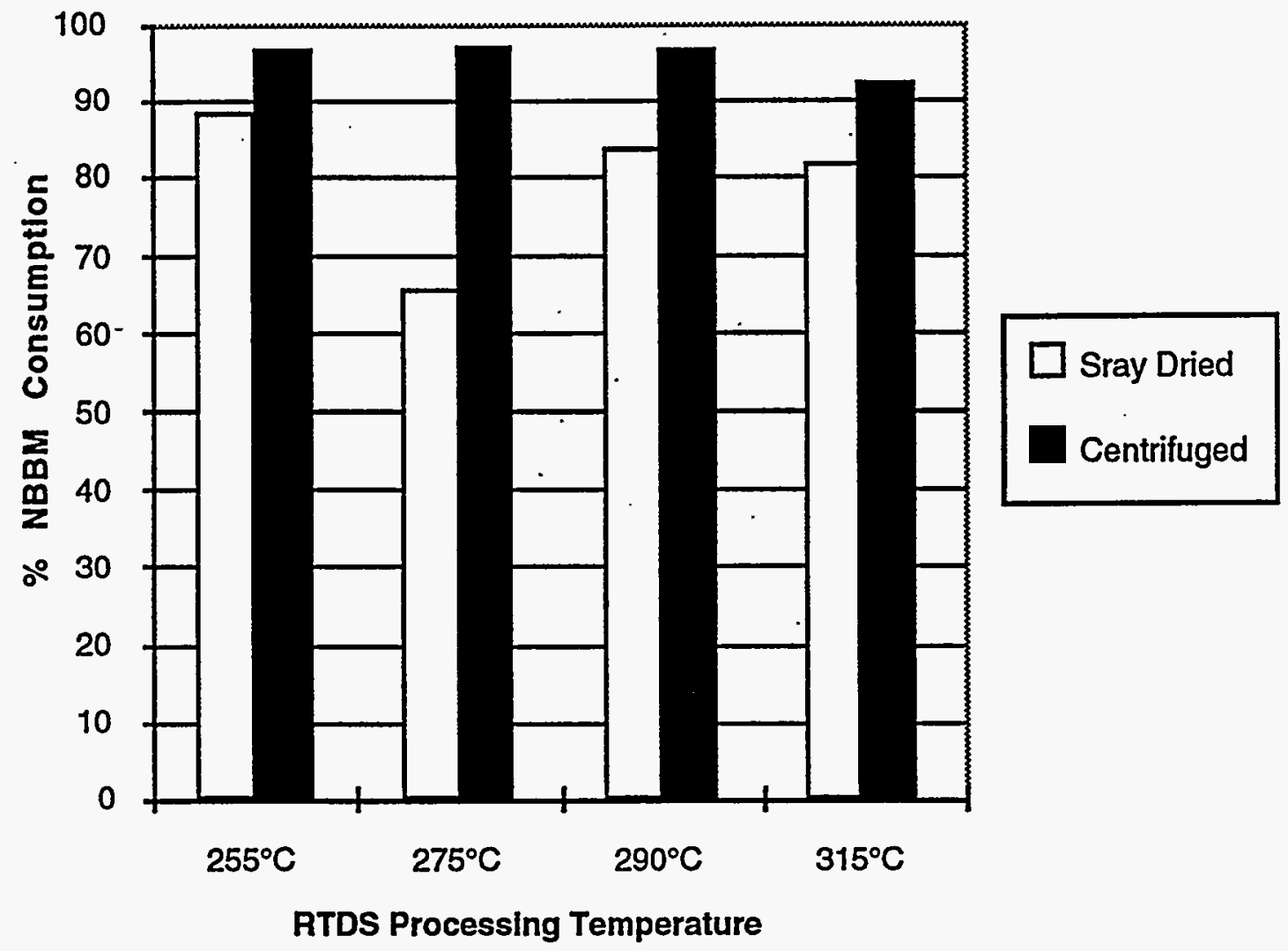

Figure 3. Effect of engineering-scale RTDS temperature and collection method on measured catalytic activity of calcined 6-line ferrihydrite powder toward consumption of NBBM model compound. 


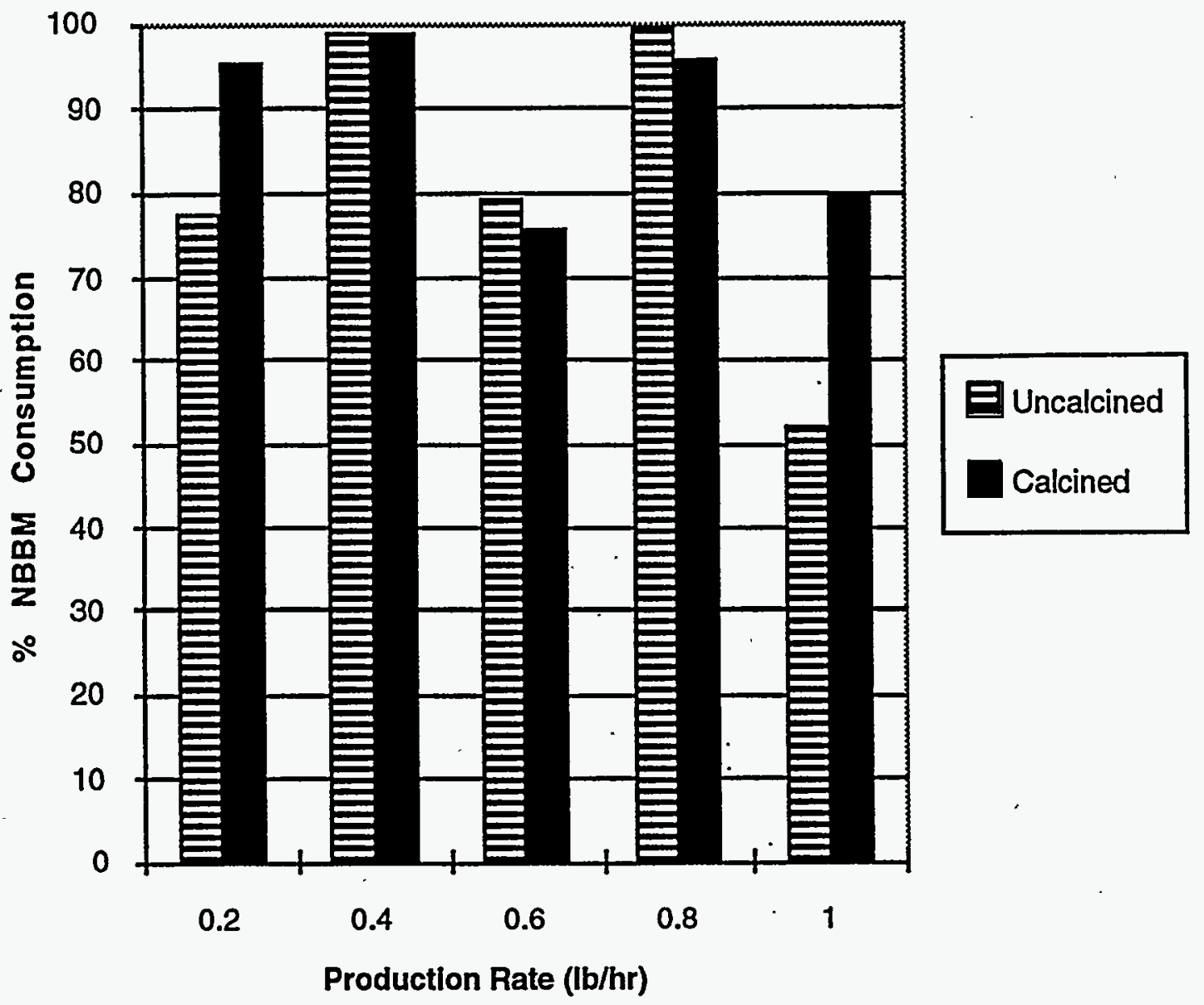

Figure 4. Activities of calcined and uncalcined 6-line ferrihydrite powders produced on the engineering-scale RTDS apparatus at increasing production rates. 